\title{
Early warning signs applied to plastic
}

Paulsen, Freja Lund; Nielsen, Maria Bille; Shashoua, Yvonne; Syberg, Kristian; Hansen, Steffen Foss

\section{Published in:}

Nature Reviews. Materials

Link to article, DOI:

10.1038/s41578-021-00317-9

Publication date:

2022

Document Version

Peer reviewed version

Link back to DTU Orbit

Citation (APA):

Paulsen, F. L., Nielsen, M. B., Shashoua, Y., Syberg, K., \& Hansen, S. F. (2022). Early warning signs applied to plastic. Nature Reviews. Materials, 7, 68-70. https://doi.org/10.1038/s41578-021-00317-9

\section{General rights}

Copyright and moral rights for the publications made accessible in the public portal are retained by the authors and/or other copyright owners and it is a condition of accessing publications that users recognise and abide by the legal requirements associated with these rights.

- Users may download and print one copy of any publication from the public portal for the purpose of private study or research.

- You may not further distribute the material or use it for any profit-making activity or commercial gain

- You may freely distribute the URL identifying the publication in the public portal

If you believe that this document breaches copyright please contact us providing details, and we will remove access to the work immediately and investigate your claim 


\section{Early warning signs applied to plastic}

Freja Lund Paulsen ${ }^{1}$, Maria Bille Nielsen ${ }^{1}$, Yvonne Shashoua ${ }^{2}$, Kristian Syberg ${ }^{3}$, Steffen Foss Hansen $^{1, *}$

${ }^{1}$ Department of Environmental Engineering, Technical University of Denmark, Lyngby, Denmark.

${ }^{2}$ Environmental Archaeology and Materials Science, National Museum of Denmark, Copenhagen, Denmark.

${ }^{3}$ Department of Science and Environment, Roskilde University, Roskilde, Denmark.

*Corresponding author (sfha@env.dtu.dk)

The European Environmental Agency (EEA) has formulated five early warning signs to be considered by regulators when it comes to new materials and substances. These warning signs reflect many concerns raised about plastics and are thus worth to be reviewed for the design and regulation of new and established polymeric materials.

Plastics are important in all areas of our daily lives, and are based on approximately 50 different polymer types. These polymers can be designed for specific applications by adding functional additives (for example, plasticizers), fillers (for example, calcium carbonate), colour (for example, pigments) and reinforcements (for example, carbon fibres). However, since the 1980s, plastics have been acknowledged as a growing environmental concern.

Based on an in-depth analyses of historical cases, such as asbestos, chlorofluorocarbons, non-ionizing radiation and mad cow disease, in 2001 the European Environmental Agency (EEA) formulated five early warning signs that regulators should be alert to when evaluating and regulating new and unknown substances for potential risk ${ }^{1}$. These early warning signs question whether the chemical, material or technology is novel, persistent, readily dispersed, bioaccumulates or causes potentially irreversible harm to human health and/or the environment. These signs reflect the concerns raised about plastics and are worth bearing in mind when considering both the development of new and the regulation of existing plastic types. In this Comment, we explore these five early warning signs in the context of different plastic types.

\section{Novelty}

Defining novelty is not trivial. The UK Royal Commission on Environmental Pollution (RCEP) ${ }^{2}$ distinguishes between new materials hitherto unused, new forms of existing materials, new applications of existing materials and new pathways for known materials.

Bakelite (phenol-formaldehyde) was the first entirely synthetic plastic, patented in 1909 as 'the material of a thousand uses'. Compared to natural polymers, such as wood, which had inspired its development, Bakelite could be rapidly moulded to produce complex forms. Bakelite was revolutionary in its extraordinarily high resistance to electricity and heat as well as its chemical 
stability and was soon widely used to insulate electrical devices (for example, light switches and radio housings) and in high-end products (for example, novelty jewelry and chess pieces).

As the world's first synthetic plastic, Bakelite would fall into RCEP's category of new materials hitherto unused. The synthetic plastics most used today include polyvinyl chloride (PVC), polypropylene (PP), polyethylene (PE), polystyrene (PS), polyethylene terephthalate (PET) and polyurethane (PUR), which were commercialized in the 1930s to the 1950s. Therefore, it could be argued that they fall into RCEP's second category of 'new forms of existing materials'. In common with other chemicals reviewed by the EEA such as halocarbons, polychlorinated biphenyls (PCBs) and methyl tert-butyl ether (MTBE), the novelty of plastics also refers to the rapid pace at which they were commercialized after the Second World War and released post-use into the environment.

\section{Persistency}

Plastics are designed to be durable and have a half-life in marine water $>60$ days, confirmed by environmental observations, which is the criteria for identifying a chemical as persistent according to Annex XIII of the European chemical legislation known as REACH. In 2019, plastic bottles were found on a Kenyan beach that dated back to March 1986, of which PE bottles were more broken, bitten or badly worn than those comprising PET $^{3}$. PET is reported as moderately stable when exposed to a marine environment, whereas PS, PVC, PUR, PE and PP exhibit less resistance to degradation ${ }^{4}$. Chemical stability is largely determined by whether the polymer consists solely of a $\mathrm{C}-\mathrm{C}$ backbone, as is the case for PS, PVC, PE and PP, or whether heteroatoms are also present, as in PET and PUR. In the first case, rapid reaction with oxygen, accelerated by UV light, is the primary cause of degradation and results in discolouration, brittleness and fragmentation. In polymeric materials that contain heteroatoms, slower reaction with water (hydrolysis) is usually the initiating step. Antiaging additives further protect plastic products from degradation during use, but are subsequently exhausted.

Fragmentation is also affected by salinity, oxidative conditions, fluctuating temperature, microbial degradation and physical stress, for example, wave movement and wind. This supports the observation that fragmentation rates of plastics are several orders of magnitude faster on beaches than in water or in marine sediments owing to lower oxygen concentrations, light intensities and temperatures ${ }^{5}$.

\section{Readily dispersed}

Widespread environmental distribution is the third warning sign suggested by the EEA. Even in areas of the world with no plastic production and limited use, plastic litter is observed on a surprising scale. For example, surveys report plastic concentrations of 1,794-100,000 items km $\mathrm{km}^{-2}$ (depending on whether fibres were taken into account) in Antarctica, including PUR, PE, PS, PP and PVC 6 . Plastic fragments and bottles originating from South America and Japan have been identified on remote islands, such as the South Sandwich Islands and South Georgia, located between South America, Africa and Antarctica, with PE, PVC, PUR, PET, PP and PS as the most abundant plastic types ${ }^{3}$. 


\section{Bioaccumulation}

According to EU's chemical legislation, substances or materials are considered to bioaccumulate, when the bioconcentration factor (BCF) in the organism is higher than 2000. The BCF is calculated by dividing the concentration of a given test substance in/on a fish or specified tissues thereof with the concentration of the substance in the surrounding medium. Plastics, such as PE, PP and PS, were found in $83 \%$ of samples of 12 different benthic invertebrates, collected in Terra Nova Bay (Ross Sea, Antarctica $)^{7}$. However, biomagnification through the food chain was not reported, because the concentration of plastic was 3-5 times higher in the filter-feeders and grazers than in omnivores and predators. These findings are supported by laboratory studies, showing lack of plastic accumulation in blue mussels (PP), zebrafish (PE), goldfish (PE), brown mussels (PVC), Daphnia magna, fathead minnow, and freshwater and marine medaka (PS). Overall, it seems that plastics are ingested by wild animals and laboratory organisms upon exposure, but may be mostly depurated after a while or once exposure ends.

\section{Potentially irreversible action}

As examples for 'potentially irreversible action', the EEA includes collapse of fish stocks as well as carcinogens, reproductive toxicants and endocrine-disrupting chemicals. Organisms at every level of the marine food chain are impacted by plastic pollution, as are all ecological compartments, although scientific evidence is somewhat lacking for soil compartments ${ }^{8}$. Even though special attention is directed towards larger and already endangered species, such as sea turtles, a general impact on marine biodiversity has been raised as a concern, based on studies showing widespread effects on marine species. For example, $17 \%$ of a total of almost 700 species found to ingestor become entangled in marine debris are classified by the International Union for Conservation of Nature's Red List of Threatened Species as near threatened, vulnerable, endangered or critically endangered ${ }^{9}$. The slow degradation of plastics in the environment and increasing pollution levels, despite mitigation efforts, result in negative environmental impacts that may not be reversible within a realistic ecological timeframe, such as impact on endangered populations of species such as sea turtles. The effect of plastics on smaller aquatic organisms has also been extensively studied ${ }^{9}$. It seems clear that plastics in particular particle sizes, such as PS nanoplastics and PE microplastics can act as vectors and cause considerable toxicity and physical damage to crustaceans when tested in combination with other environmental pollutants such as mercury.

In addition to the direct impact of plastic, a range of problematic chemicals are linked to plastic pollution. For example, chemicals originating from plastic packaging are associated with the highest possible human health (63 substances) and environmental hazard classification (68 substances) in the $\mathrm{EU}^{10}$. Although the presence of classified substances does not necessarily equal irreversible harm, 7 of those substances were classified as either persistent, bioaccumulative and toxic or very persistent and very bioaccumulative, and 15 as endocrine-disrupting chemicals.

\section{Conclusions and outlook}

When investigating the EEA early warning signs for what we know about different plastic types, it becomes clear that these warning signs, except for bioaccumulation (data on bioaccumulation of 
nanoplastics are still insufficient), are relevant for plastics. It is important to note that plastic is not just plastic and that chemical structures and additives influence dispersibility and persistency as well as potential for uses and possible environmental impacts. The available information and data do not allow precise differentiation between plastic types in relation to the EEA early warning signs. This is a serious omission and can oversimplify the regulations associated with our use of various plastics.

New uses of plastics are continuously identified and new formulations are being developed, making plastic an ongoing novel material almost by default. What would truly lay the foundation for the next 'polymer age' would be the design and formulation of plastic types that do not fulfill any of the EEA early warning signs.

\section{Acknowledgments statement}

The authors gratefully acknowledge Velux Fonden's financial support of the MarinePlastic project.

\section{Author contributions}

All authors contributed equally to the preparation of this manuscript.

\section{Competing interests}

The authors declare that they have no competing interests.

\section{References}

\footnotetext{
${ }^{1}$ EEA. Late Lessons From Early Warnings: The Precautionary Principle 1896-2000 (European Environmental Agency, Copenhagen, 2001). https://www.eea.europa.eu/publications/environmental_issue_report_2001_22/Issue_Report_No_22.pdf/view ${ }^{2}$ RCEP. Twenty-Seventh Report Novel Materials in the Environment: The Case of Nanotechnology. (Royal Commission on Environmental Pollution, Norwich, 2008).

${ }^{3}$ Ryan, P.G. Land or sea? What bottles tell us about the origins of beach litter in Kenya. Waste Manage. 116, 49-57 (2020).

${ }^{4}$ Kyungjun, M., Cuiffi, J.D. \& Mathers, R.T. Ranking environmental degradation trends of plastic marine debris based on physical properties and molecular structure. Nat. Commun. 11:727 (2020).

${ }^{5}$ GESAMP. Sources, fate and effects of microplastics in the marine environment: a global assessment (Joint Group of Experts on the Scientific Aspects of Marine Environmental Protection, International Maritime Organization, London, 2015).

${ }^{6}$ Waller, C.L. et al. Microplastics in the Antarctic marine system: An emerging area of research. Sci. Total Environ. 598:220-227 (2017).

${ }^{7}$ Sfriso, A.A.A. et al. Microplastic accumulation in benthic invertebrates in Terra Nova Bay (Ross Sea, Antarctica). Environ. Int. 137:105587 (2020).

${ }^{8}$ Bucci, K., Tulio, M. \& Rochman, C. M. What is known and unknown about the effects of plastic pollution: A metaanalysis and systematic review. Ecol. Appl. 30(2):e02044. 10.1002/eap.2044 (2020).

${ }^{9}$ Gall, S.C. \& Thompson, R.C. The impact of debris on marine life. Mar. Pollut. Bull. 92(1-2):170-179 (2015).

${ }^{10}$ Groh et al. Overview of known plastic packaging-associated chemicals and their hazards. Sci. Total Environ. 651:3253-3268 (2019).
} 